\title{
Is Sexual Dimorphism in the Immune Response of Gryllodes sigillatus Related to the Quality of Diet?
}

\author{
Adolfo Galicia, ${ }^{1}$ Raúl Cueva del Castillo, ${ }^{1}$ and Jorge Contreras-Garduño² \\ ${ }^{1}$ Uiversidad Nacional Autonoma de Mexico FES Iztacala, UBIPRO, Laboratoria de Ecología, Avenida de los Barrios, \\ Number 1 Los Reyes Iztacala, A.P. 314, 54090 México, MX, Mexico \\ ${ }^{2}$ División de Ciencias Naturales y Exactas, Universidad de Guanajuato, Campus Guanajuato, Noria Alta s/ $n$, Noria Alta, \\ 36050 Guanajuato, GTO, Mexico
}

Correspondence should be addressed to Jorge Contreras-Garduño; ja.contreras@ugto.mx

Received 24 August 2013; Accepted 30 December 2013; Published 20 March 2014

Academic Editors: M. Friedrich, M. L. Hale, and Y. Park

Copyright (C) 2014 Adolfo Galicia et al. This is an open access article distributed under the Creative Commons Attribution License, which permits unrestricted use, distribution, and reproduction in any medium, provided the original work is properly cited.

Whereas some authors have proposed that sexual dimorphism in the immune response is fixed, others pose that it is dynamic and depends on diet. The aim of the present study was to explore the second hypothesis. Immunocompetence differences between females and males can be linked to resource availability. We tested this idea by providing a low or high quality diet to two groups of Gryllodes sigilatus during their developmental period. Then, at the adult phase half of each group was challenged with LPS from Serratia marcescens. The size, phenol oxidase (PO), and lytic activity were compared between groups according to diet, sex, and immune challenge. Results show that diet quality favor size in both sexes. However, the overall immune response did not seem to be significantly different based on diet, but instead on sex. Females showed greater phenol oxidase levels than males, but the opposite was found with lytic activity. Perhaps in G. sigillatus the differences in the pathogens commonly confronted by each sex in the distinct habitat of each could explain the differences on PO and lytic activity.

\section{Introduction}

The understanding of sexual dimorphism (SD) is one of the central challenges in evolutionary biology. SD includes differences in behavior, morphology, and physiology, but perhaps why males are less resistant to parasites and pathogens than females is one of the most studied questions regarding this topic [1-3]. The underlying physiological mechanism of this dimorphic resistance could be that females are more immunocompetent than males, implying SD in the immune response. Hence, immunocompetence is defined as the magnitude and effectiveness of immune response [4].

To understand why females are more immunocompetent than males can be explained by two hypotheses: sexual selection $[2,5]$ and the immunocompetence handicap hypothesis [6]. The sexual selection hypothesis suggests that males in most species invest in their sexual traits at the expense of survival, meaning that fewer resources are invested in the immune response [2]. For example, males in Panorpa vulgaris provide nuptial gifts to attract a female but have the lower values of phagocytic and lysozyme activity [7]. The second hypothesis known as the immunocompetence handicap hypothesis considers that females invest in the immune response to favor longevity, which is positively correlated with fecundity [8]. However, there are no studies that have tested whether female longevity and egg production are positively correlated with the immune response [8]. The problem with the sexual selection and the immunocompetence handicap hypotheses is that there are some cases in which males are more immunocompetent than females and others in which no differences have been found between sexes [8]. For example, in the tree weta (Hemideina crassidens) there was no significant relationship between immune response and weapon or testes size in males or fecundity in females [9]. In addition, in Teleogryllus commodus males showed stronger immune response than females, but in T. oceanicus no sex differences were found [10]. In general, in invertebrates, females seem not to be more immunocompetent or resistant 
sex [11]. Thus, the question is why males are in some cases more immunocompetent and in other cases females.

A third hypothesis suggests that, rather than being fixed, the immune response is plastic and limited by resource availability [12]. McKean and Nunney [12] found that with abundant food, D. melanogaster males and females experienced no differences in immunity and females produced a large number of eggs, but immunity was reduced for both males and females when food provision was low and sexual activity was intense. It has been reported that nutritional status is related to immune response $[13,14]$, but this particular hypothesis suggests a physiological plasticity regarding immunity which depends on sex and food availability [10, 12]. Although this hypothesis could explain differences between females and males on immunocompetence, most researchers have paid little attention to this hypothesis.

Crickets have been a good model system to study SD in immune response. For example, in Gryllus texensis fed ad libitum, phenol oxidase activity and haemocyte number varied according to the sex and age of experimental subjects [15]. In the prereproductive period of these animals, male and female immunocompetence was similar. However, when males displayed reproductive behavior, phenol oxidase (PO) activity declined compared to females and younger males [15]. On the other hand, with the onset of sexual behavior in females, PO activity increased relative to female nymphs and prereproductive adult females [15]. In another cricket (T. oceanicus) Zuk et al. [10] showed that under normal food conditions no sexual differences were found, but under starving conditions males had a stronger immune response (encapsulation response) than females.

Here, the interaction between sex, diet, and immune challenge was tested using Gryllodes sigillatus as model system. The advantage of using this system is that males live longer than females [16]. Hence, according to the (a) immunocompetence handicap hypothesis, a better immune response is expected in males than in females; (b) the sexual selection hypothesis, males should have a lower immune response than females; and (c) plastic sexual dimorphism dependent on diet, the better feed sex should have the better immune response. Given that more than one immune response parameter should be employed to evaluate immunocompetence $[17,18]$, we measured two immune markers of the innate immune response of these insectsPO and lytic activity-both of which have previously been recorded in crickets $[4,17,18]$ including G. sigillatus [19]. During melanogenesis PO catalyzes the hydroxylation of tyrosine to L-dihydroxy phenylalanine (L-DOPA) to produce the melanin precursor, indolequinone, to combat parasites and pathogens [20]. Quinoid compounds are potent catalysts of the production of reactive oxygen molecules (ROS) [20, 21], and the oxidation of dihydroxy phenylalanine (L-DOPA) can generate superoxide anion and hydrogen peroxide, which are toxic molecules to parasites [20-22]. An increase of lytic activity has also been implicated in resistance to a bacterial challenge [23]. To activate the immune response we used lipopolysaccharides of $S$. marcescens, a highly pathogenic bacterium for insects that has been shown to activate PO and lytic activity in crickets [4] including G. sigillatus [24].

\section{Materials and Methods}

2.1. Species. G. sigillatus is known to be sexually dimorphic and is denominated the decorated cricket. This species was originally described from specimens collected in Sri Lanka [25]. At present it is well established in tropical urban ecosystems around the world $[26,27]$. Females are flightless and larger than males. Male wing expanse only covers the thorax area, and therefore these wings are smaller than those of other cricket species. At night in the field, females are phonetically attracted to males and they oviposit soon after mating, and the eggs hatch approximately 30 days after copulation [28]. Nutritional stress has a negative impact on female and male body size as well as on time and stability of offspring development $[29,30]$. In males, body size is related to mating success. Thorax width and right hind leg length are negatively correlated with song pulse, and shorter pulse is preferred by the females [31].

2.2. Cricket Collection and Rearing. We established a colony from last instar nymphs collected in Zapotitlán Salinas, Puebla, Mexico (latitude: $18^{\circ} 16^{\prime} 59^{\prime \prime} \mathrm{N}$; longitude: $97^{\circ} 26^{\prime} 51^{\prime \prime} \mathrm{W}$; $1480 \mathrm{~m}$ above sea level). The collecting site is xerophytic shrub land with an annual precipitation of $412 \mathrm{~mm}$. Animals were maintained in environmental conditions at $29 \pm 1^{\circ} \mathrm{C}$ with $\mathrm{L} / \mathrm{D}$ periods of $12 \mathrm{~h}$. They were provided ad libitum with water vials and a Purina chicken diet (Start \& Grow). The colony was regularly supplied with new individuals to avoid inbreeding. Second instar nymphs were removed from the colony and placed individually in $55 \mathrm{~mL}$ transparent plastic jars. The nymphs were randomly assigned to a high or a low quality diet. The high quality diet (protein diet, $\mathrm{H}$ ) consisted of $90 \%$ rabbit food and $10 \%$ bran, and the low quality diet (L) $10 \%$ rabbit brand food and $90 \%$ bran. When crickets became adults we measured (with a digital caliper; Mitutoyo Corp., Tokyo, Japan) thorax width and right femur III length for both sexes.

2.3. Immune Challenge. Animals were divided according to diet (low and high quality) and sex and afterwards subdivided into two groups. One of them was challenged (experimental group) and the other unchallenged (control group). The challenge was administered inside the thorax of each cricket [4] by using a $10 \mu \mathrm{L}$ syringe (Hamilton) to inoculate $2 \mu \mathrm{L}$ of phosphate buffer saline (PBS, Sigma, $\mathrm{pH} 7.4$ ) with $10 \mu \mathrm{g}$ of lipopolysaccharides (LPS) from $S$. marcescens (Sigma). The control animals received only an injection of $2 \mu \mathrm{L}$ PBS. Both challenged and control groups were housed individually in plastic, transparent containers $\left(10 \mathrm{~cm}^{3}\right)$ for one hour.

A three-way factorial design was established (sex, diet, and challenge). The three factors have two levels that were crossed to yield 8 different treatment combinations: males with a low quality diet that were challenged (MLC; $n=76$ ) or unchallenged (MLU; $n=65$ ), males with a high quality diet that were challenged (MHC; $n=40$ ) or unchallenged (MHU; $n=46$ ), females with a low quality diet that were challenged (FLC; $n=92$ ) or unchallenged (FLU; $n=69$ ), and females with a high quality diet that were challenged (FHC; 
TABLE 1: Effect of sex, diet, challenge, and their interactions on the amount PO in haemolymph.

\begin{tabular}{lccccc}
\hline & SS & DF & MS & $F$ & $P$ \\
\hline Sex & 238130 & 1 & 238130 & 11.480 & 0.0007 \\
Diet & 23150 & 1 & 23150 & 1.116 & 0.29 \\
Challenge & 2937 & 1 & 2937 & 0.142 & 0.70 \\
Sex $*$ diet & 3444 & 1 & 3444 & 0.166 & 0.68 \\
Sex $*$ challenge & 38 & 1 & 38 & 0.002 & 0.97 \\
Diet * challenge & 635 & 1 & 635 & 0.031 & 0.86 \\
Sex $*$ diet $*$ challenge & 47194 & 1 & 47194 & 2.275 & 0.13 \\
Error & 10247094 & 494 & 20743 & & \\
\hline
\end{tabular}

SS: sum of squares; DF: degrees of freedom; MS: mean square; $F$ : test value; $P$ : significance.

$n=68$ ) or unchallenged (FHU; $n=56$ ). In each of these groups we recorded size, haemolymph protein content, and phenol oxidase and lytic activity.

2.4. Haemolymph. One hour after bacterial challenge (or injection of PBS only), the haemolymph was obtained by perfusion. A syringe ( $10 \mu \mathrm{L}$, Hamilton) was used to inject $5 \mu \mathrm{L}$ of PBS in each animal thorax, and then a puncture in the coxa allowed the emanation of a drop of haemolymph. Five $\mu \mathrm{L}$ of haemolymph were collected with a micropipette (Rainin, $10 \mu \mathrm{L}$ ) and deposited in a precooled vial of $1.5 \mathrm{~mL}$ (Eppendorf) that contained protease inhibitors (Sigma) and $80 \mu \mathrm{L}$ of PBS (see [32]). Tubes were stored at $-70^{\circ} \mathrm{C}$ and analyzed the next day.

2.5. Phenol Oxidase. To estimate PO activity in each sample, an aliquot with $40 \mu \mathrm{L}$ of haemolymph/PBS was deposited in a microplate template of 96 round-bottomed wells (Corning) that contained $60 \mu \mathrm{L}$ of PBS and $100 \mu \mathrm{L}$ of L-DOPA diluted in PBS $(4 \mathrm{mg} / \mathrm{mL})$. PO activity was determined indirectly by oxidation of 3,4-Dihydroxy-L-phenylalanine (L-DOPA, Sigma). As blanks, only $50 \mu \mathrm{L}$ of PBS and $50 \mu \mathrm{L}$ of L-DOPA $(4 \mathrm{mg} / \mathrm{mL})$ were used. The slope of the curve was calculated by using the optical density at $490 \mathrm{~nm}$ with an ELISA reader (Microplate Reader Series, BMG LABTECH). Optical density readings were taken every 5 minutes during one hour at $27^{\circ} \mathrm{C}$.

2.6. Lytic Activity. To estimate the lytic activity, $9 \mathrm{mg}$ of Micrococcus luteus (Sigma) were dissolved in $25 \mathrm{~mL}$ of Phosphate buffer solution $(0.1 \mathrm{M}$, Sigma). An aliquot $(200 \mu \mathrm{L})$ of the $M$. luteus diluted in phosphate buffer solution was mixed with $30 \mu \mathrm{L}$ of each sample. Only $0.1 \mathrm{M}$ phosphate buffer solution $(230 \mu \mathrm{L})$ were used as control. All samples were added to each well of a microplate template of 96 roundbottomed wells. Samples were read every 5 minute during ten minutes at $540 \mathrm{~nm}$ with an ELISA reader (Microplate Reader Series, BMGLABTECH) and the slope of the curve was calculated for comparison between groups.

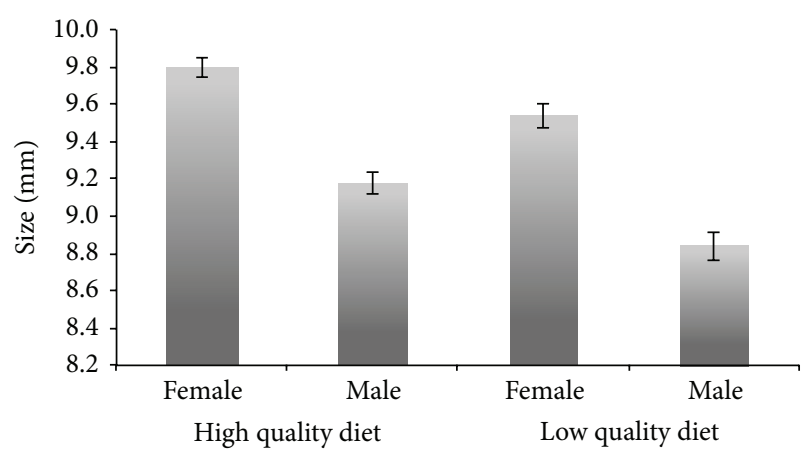

Figure 1: Crickets size (femur length) according to sex and diet. Mean \pm SE is shown.

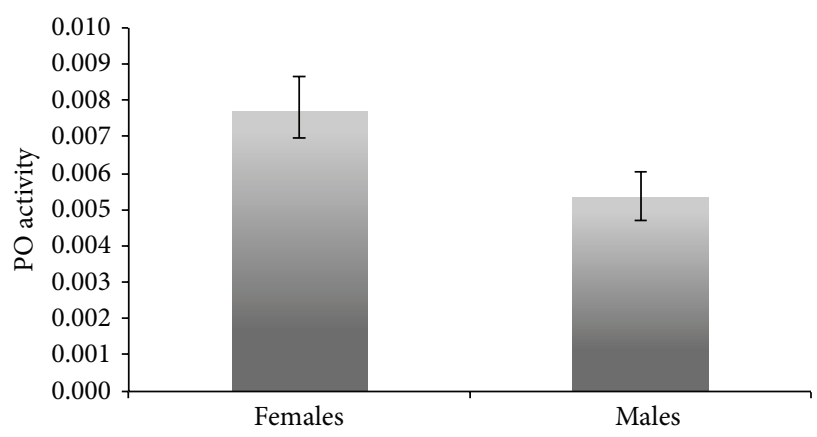

FIGURE 2: Sexual differences according to phenol oxidase activity. Mean \pm SE is shown.

\section{Results}

3.1. Size (Femur Length). Size was affected by sex $\left(F_{1-508}=\right.$ $106.9 ; P<0.0001)$ and $\operatorname{diet}\left(F_{1-508}=21.9 ; P<0.0001\right)$ but the interaction size $*$ diet was not significant $\left(F_{1-508}=0.4 ; P=\right.$ $0.52)$. Females $(9.68 \pm 0.04 ; n=284)$ were larger than males $(9.05 \pm 0.04 ; n=226)$. However, females $(9.79 \pm 0.05 ; n=$ $160)$ and males $(9.53 \pm 0.06 ; n=141)$ reared on high quality diet were larger than females $(9.1 \pm 0.06 ; n=124$; Fisher LSD $P=0.002)$ and males $(8.83 \pm 0.07 ; n=85$; Fisher LSD $P=$ 0.0004 ) reared on low quality diet, respectively (Figure 1).

3.2. Phenol Oxidase. In a three-way analysis of variance the results did not indicate significant difference in $\mathrm{PO}$ activity between treatments (Table $1 ; F_{6-480}=1.31 ; P=0.24$ ). Only sex explained the variation in the $\mathrm{PO}$ activity. Females had more PO $(0.0078 \pm 0.0008)$ than males $(0.0053 \pm 0.0006$, Figure 2$)$.

3.3. Lytic Activity. The results showed a significant difference in lytic activity between treatments $\left(F_{6-480}=3.45 ; P<\right.$ $0.0001)$. Sex and challenge explained the variation in the amount of lytic activity. The immune challenge increased lytic activity $(0.0077 \pm 0.0003)$ compared to controls $(0.0071 \pm$ 0.0003 , Figure $3(\mathrm{a})$ ). In terms of sex, females had less lytic activity $(0.0066 \pm 0.0003)$ than males $(0.0082 \pm 0.0004$, Figure 3(b)). 


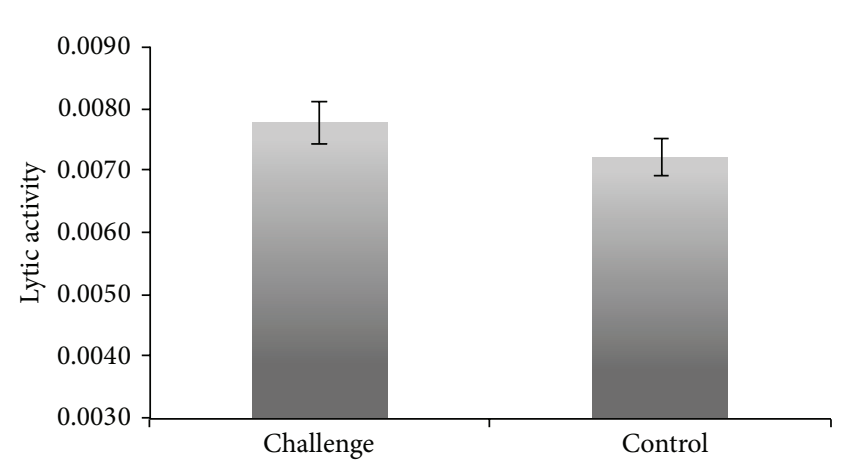

(a)

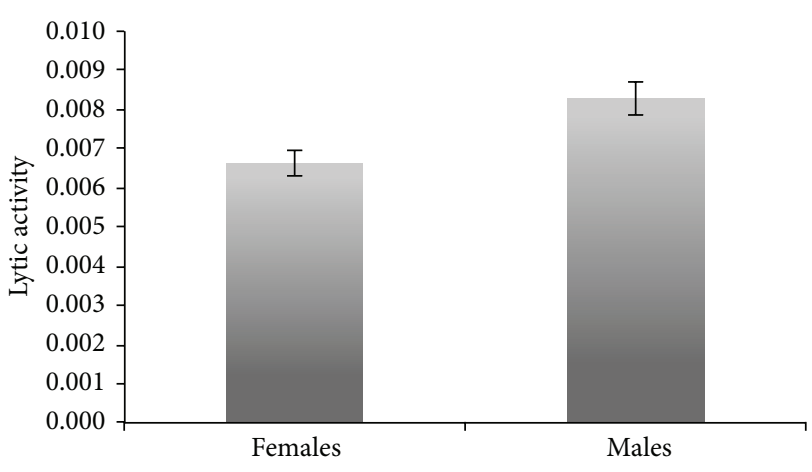

(b)

FIgURE 3: Sexual differences according to Lytic activity and challenge. Mean $\pm \mathrm{SE}$ is shown.

\section{Discussion}

Regarding sexual dimorphism (SD), some authors suggest that it is fixed, males being less immunocompetent than females $[1,5,6]$, while others pose that it is dynamic and depends upon diet $[10,12]$. Comparing $G$. sigillatus fed a high and low quality diet in the present study, it was found that a better diet resulted in larger crickets but did not affect the immune response (evidenced by the unchanged PO and lytic activity). On the other hand, females showed greater phenol oxidase levels than males, but the opposite was found with lytic activity.

In some species, such as Spodoptera littoralis [33] and Anabrus simplex [18], the amount of protein is related to the immune response. However, in these reports only one immune response marker was evaluated. Other reports indicate that diet protein increases some but not all immune markers. For example, food limitation during immature stages of $G$. campestris reduces lysozyme activity in the adult stage but does not have any effect on PO activity [34]. In A. simplex the access to a high-protein diet increases PO activity but not the encapsulation response or lytic activity [18]. These studies reveal that the plasticity of the immune response is related to the diet protein content. However, in the current study SD in the immune response of G. sigillatus is not affected by food protein and, together, all these results suggest a complex relationship between immune response and food quality.

The immunocompetence handicap hypothesis and the sexual selection hypothesis suggest that the immune response is fixed. The former states that, if female fecundity and longevity are positively correlated, an overall immune response should be better and longevity higher in females than in males [6]. The latter, taking into account that both sexual traits and immunity are costly, asserts that males should invest their resources in sexual traits at the expense of longevity (e.g., the immune response; $[1,5]$ ). In G. sigillatus, males survival is longer than females [16], so, according to the former hypothesis it was expected to have more elevated values of immune response in males than in females, but according to the latter hypothesis the opposite was expected. Hence, our results do not support either of these scenarios because some but not all immune parameters were increased in females and decreased in males. Similarly, SD in $P$. zoe was found to be dependent on the particular immune marker: the black winged male morph showed lower levels of nitric oxide but higher levels of PO than that of females [35]. The insect immune response is highly dynamic and it varies depending on different physiological contexts as well as its interaction with different parasites [36] and a single measurement of immunity should not be interpreted as a demonstration of overall resistance $[4,17,37,38]$.

The immunocompetence handicap hypothesis and the sexual selection hypothesis explain the evolution of SD from the host point of view. However, a third scenario is the role of parasites in sexual differences $[39,40]$. For example, female monarch butterflies (Danaus plexippus) had greater haemocyte counts than males in the absence of infection with Ophryocystis elektroscirrha, but the opposite was found in the presence of infection [41]. It is the parasite and pathogen hypothesis that allows us to explain the higher levels of PO in $G$. sigillatus females and the greater lytic activity of males. Whereas PO is responsible for combatting macroparasites, such as nematodes and parasitoids [42-44], lytic activity is related to resistance to bacteria (including $S$. marcescens). Thus, it is possible that females of G. sigillatus are more exposed to macroparasites than males and that males are more frequently attacked by bacteria. In line with this, $G$. sigillatus is attacked by the nematode Mehdinema alii [45]. This nematode is innocuous to females but infective for males [45]. The proposals as to why females are more resistant than males are that nematodes could require sex specific nutrients or that the anatomy of females could impede the dauers entrance to the intestine [45]. However, an alternative hypothesis is that females better control nematodes growing by producing more PO than males. Finally, apart from the idea that females have greater resistance against this nematode than males because it exists in their habitat, it is also possible that females produce more PO than males because this molecule is also used to produce eggs $[46,47]$. Hence, if parasites play a key role in $\mathrm{SD}$, males should be more resistant than females against bacteria because we found that male lytic activity was activated against LPS of $S$. marcescens. This should certainly be an interesting topic for future research 
because the sexual dimorphism could not solely be related to sexual selection and longevity but how sexes invest their resources on immune defense, condition, and reproduction at the same time as they confront parasites with different virulence or different food quality, or reproductive history [40].

In conclusion, the current results do not support our hypothesis that diet should affect SD in the immune response. Since neither immune marker recorded was affected by diet, the costliness of production of either does not seem to be based on resource availability in Gryllus sigillatus. The fact that females showed more $\mathrm{PO}$ activity than males but less lytic activity has two implications. Firstly, it supports the idea that more than one immune marker should be recorded in studies of immunocompetence [36]. Secondly, it suggests that future studies should explore the possible relation between SD in the immune response and the parasites and pathogens that differentially affect each sex.

\section{Conflict of Interests}

The authors declare no financial relation with the trademarks mentioned in this paper as well as no conflict of interests.

\section{Acknowledgments}

Five anonymous reviewers improved substantially the manuscript. RCDC was supported by a grant from PAPIIT (Grant no. IN206109) and JCG was supported from CONACyT (Grant no. 152666) and PROMEP (Grant no. 103.5/10/4684).

\section{References}

[1] M. Zuk and K. A. McKean, "Sex differences in parasite infections: patterns and processes," International Journal for Parasitology, vol. 26, no. 10, pp. 1009-1024, 1996.

[2] M. Zuk and A. M. Stoehr, "Immune defense and host life history," American Naturalist, vol. 160, supplement 4, pp. S9S22, 2002.

[3] M. Zuk, “The sicker sex," PLoS Pathogens, vol. 5, no. 1, Article ID e1000267, 2009.

[4] S. A. Adamo, "Estimating disease resistance in insects: phenoloxidase and lysozyme-like activity and disease resistance in the cricket Gryllus texensis," Journal of Insect Physiology, vol. 50, no. 2-3, pp. 209-216, 2004.

[5] M. Zuk, "Reproductive strategies and disease susceptibility: an evolutionary viewpoint," Parasitology Today, vol. 6, no. 7, pp. 231-233, 1990.

[6] J. Rolff, "Bateman's principle and immunity," Proceedings of the Royal Society B: Biological Sciences, vol. 269, no. 1493, pp. 867872, 2002.

[7] J. Kurtz and K. P. Sauer, "The immunocompetence handicap hypothesis: testing the genetic predictions," Proceedings of the Royal Society B: Biological Sciences, vol. 266, no. 1437, pp. 25152522, 1999.

[8] C. L. Nunn, P. Lindenfors, E. R. Pursall, and J. Rolff, "On sexual dimorphism in immune function," Philosophical Transactions of the Royal Society B: Biological Sciences, vol. 364, no. 1513, pp. 6169, 2009.
[9] C. D. Kelly and M. D. Jennions, "Sexually dimorphic immune response in the harem polygynous Wellington tree weta Hemideina crassidens," Physiological Entomology, vol. 34, no. 2, pp. 174-179, 2009.

[10] M. Zuk, L. W. Simmons, J. T. Rotenberry, and A. M. Stoehr, "Sex differences in immunity in two species of field crickets," Canadian Journal of Zoology, vol. 82, no. 4, pp. 627-634, 2004.

[11] L. A. D. Sheridan, R. Poulin, D. F. Ward, and M. Zuk, "Sex differences in parasitic infections among arthropod hosts: is there a male bias?" Oikos, vol. 88, no. 2, pp. 327-334, 2000.

[12] K. A. McKean and L. Nunney, "Bateman's principle and immunity: phenotypically plastic reproductive strategies predict changes in immunological sex differences," Evolution, vol. 59, no. 7, pp. 1510-1517, 2005.

[13] M. T. Siva-Jothy and J. J. W. Thompson, "Short-term nutrient deprivation affects immune function," Physiological Entomology, vol. 27, no. 3, pp. 206-212, 2002.

[14] T. M. Valtonen, A. Kleino, M. Rämet, and M. J. Rantala, "Starvation reveals maintenance cost of humoral immunity," Evolutionary Biology, vol. 37, no. 1, pp. 49-57, 2010.

[15] S. A. Adamo, M. Jensen, and M. Younger, "Changes in lifetime immunocompetence in male and female Gryllus texensis (formerly G. integer) *: trade-offs between immunity and reproduction," Animal Behaviour, vol. 62, no. 3, pp. 417-425, 2001.

[16] C. R. Archer, F. Zajitschek, S. K. Sakaluk, N. J. Royle, and J. Hunt, "Sexual selection affects the evolution of lifespan and ageing in the decorated cricket Gryllodes sigillatus," Evolution, vol. 66, no. 10, pp. 3088-3100, 2012.

[17] S. A. Adamo, "How should behavioural ecologists interpret measurements of immunity?" Animal Behaviour, vol. 68, no. 6, pp. 1443-1449, 2004.

[18] R. B. Srygley, P. D. Lorch, S. J. Simpson, and G. A. Sword, "Immediate protein dietary effects on movement and the generalised immunocompetence of migrating Mormon crickets Anabrus simplex (Orthoptera: Tettigoniidae)," Ecological Entomology, vol. 34, no. 5, pp. 663-668, 2009.

[19] S. N. Gershman, C. A. Barnett, A. M. Pettinger, C. B. Weddle, J. Hunt, and S. K. Sakaluk, "Give 'til it hurts: trade-offs between immunity and male reproductive effort in the decorated cricket, Gryllodes sigillatus," Journal of Evolutionary Biology, vol. 23, no. 4, pp. 829-839, 2010.

[20] A. J. Nappi and E. Vass, "Melanogenesis and the generation of cytotoxic molecules during insect cellular immune reactions," Pigment Cell Research, vol. 6, no. 3, pp. 117-126, 1993.

[21] A. J. Nappi, E. Vass, F. Frey, and Y. Carton, "Superoxide anion generation in Drosophila during melanotic encapsulation of parasites," European Journal of Cell Biology, vol. 68, no. 4, pp. 450-456, 1995.

[22] A. J. Nappi and E. Ottaviani, "Cytotoxicity and cytotoxic molecules in invertebrates," BioEssays, vol. 22, no. 5, pp. 469480, 2000.

[23] R. Wilson and N. A. Ratcliffe, "Effect of lysozyme on the lectinmediated phagocytosis of Bacillus cereus by haemocytes of the cockroach, Blaberus discoidalis," Journal of Insect Physiology, vol. 46, no. 5, pp. 663-670, 2000.

[24] A. M. Kerr, S. N. Gershman, and S. K. Sakaluk, "Experimentally induced spermatophore production and immune responses reveal a trade-off in crickets," Behavioral Ecology, vol. 21, no. 3, pp. 647-654, 2010.

[25] F. Walker, "Characters of some apparently undescribed Ceylon insects (II)," Annals and Magazine of Natural History, vol. 4, no. 3, pp. 217-244, 1859. 
[26] M. Hebard, "New species and records of Mexican Orthoptera," Transactions of American Entomological Society, vol. 58, pp. 201371, 1932.

[27] R. L. Smith and W. B. Thomas, "Southwestern distribution and habitat ecology of Gryllodes supplicans," Bulletin of Entomological Society of America, vol. 34, no. 4, pp. 186-190, 1988.

[28] S. K. Sakaluk, "Reproductive behaviour of the decorated cricket, Gryllodes supplicans (Orthoptera: Gryllidae): calling schedules, spatial distribution, and mating," Behaviour, vol. 100, no. 1-4, pp. 202-225, 1987.

[29] S. K. Sakaluk, J. M. Schaus, A. Eggert, W. A. Snedden, and P. L. Brady, "Polyandry and fitness of offspring reared under varying nutritional stress in decorated crickets," Evolution, vol. 56, no. 10, pp. 1999-2007, 2002.

[30] S. T. Mallard and C. J. Barnard, "Food stress, fluctuating asymmetry and reproductive performance in the gryllid crickets Gryllus bimaculatus and Gryllodes sigillatus," Behaviour, vol. 141, no. 2, pp. 219-232, 2004.

[31] J. Champagnon and R. Cueva Del Castillo, "Female mate choice, calling song and genetic variance in the cricket, Gryllodes sigillatus," Ethology, vol. 114, no. 3, pp. 223-230, 2008.

[32] J. Contreras-Garduño, H. Lanz-Mendoza, and A. CórdobaAguilar, "The expression of a sexually selected trait correlates with different immune defense components and survival in males of the American rubyspot," Journal of Insect Physiology, vol. 53, no. 6, pp. 612-621, 2007.

[33] K. P. Lee, J. S. Cory, K. Wilson, D. Raubenheimer, and S. J. Simpson, "Flexible diet choice offsets protein costs of pathogen resistance in a caterpillar," Proceedings of the Royal Society B: Biological Sciences, vol. 273, no. 1588, pp. 823-829, 2006.

[34] A. Jacot, H. Scheuber, J. Kurtz, and M. W. G. Brinkhof, “Juvenile immune system activation induces a costly upregulation of adult immunity in field crickets Gryllus campestris," Proceedings of the Royal Society B: Biological Sciences, vol. 272, no. 1558, pp. 63-69, 2005.

[35] G. Ruiz-Guzmán, J. Canales-Lazcano, J. G. Jiménez-Cortés, and J. Contreras-Garduño, "Sexual dimorphism in immune response: testing the hypothesis in an insect species with two male morphs," Insect Science, vol. 20, no. 5, pp. 620-628, 2013.

[36] S. A. Adamo, "The importance of physiology for ecoimmunology: lessons from the insects," in Ecoimmunology, G. E. Demas and R. J. Nelson, Eds., Oxford University Press, Oxford, UK, 2012.

[37] K. Boa-Amponsem, C. T. Larsen, E. A. Dunnington, and P. B. Siegel, "Immunocompetence and resistance to marble spleen disease of broiler- and layer-type pure lines of chickens," Avian Pathology, vol. 28, no. 4, pp. 379-384, 1999.

[38] M. J. Rantala and D. A. Roff, "An analysis of trade-offs in immune function, body size and development time in the Mediterranean Field Cricket, Gryllus bimaculatus," Functional Ecology, vol. 19, no. 2, pp. 323-330, 2005.

[39] D. Duneau and D. Ebert, "Host sexual dimorphism and parasite adaptation,” PLoS Biology, vol. 10, no. 2, Article ID e1001271, 2012.

[40] A. M. Stoehr and H. Kokko, "Sexual dimorphism in immunocompetence: what does life-history theory predict?" Behavioral Ecology, vol. 17, no. 5, pp. 751-756, 2006.

[41] E. A. Lindsey and S. Altizer, "Sex differences in immune defenses and response to parasitism in monarch butterflies," Evolutionary Ecology, vol. 23, no. 4, pp. 607-620, 2009.
[42] B. Lemaitre and J. Hoffmann, "The host defense of Drosophila melanogaster," Annual Review of Immunology, vol. 25, pp. 697743, 2007.

[43] Y. Carton, M. Poirié, and A. J. Nappi, "Insect immune resistance to parasitoids," Insect Science, vol. 15, no. 1, pp. 67-87, 2008.

[44] J. C. Castillo, S. E. Reynolds, and I. Eleftherianos, "Insect immune responses to nematode parasites," Trends in Parasitology, vol. 27, no. 12, pp. 537-547, 2011.

[45] L. T. Luong, E. G. Platzer, M. Zuk, and R. M. Giblin-Davis, "Venereal worms: sexually transmitted nematodes in the decorated cricket," Journal of Parasitology, vol. 86, no. 3, pp. 471-477, 2000.

[46] J. Li and B. M. Christensen, "Involvement of l-tyrosine and phenol oxidase in the tanning of Aedes aegypti eggs," Insect Biochemistry and Molecular Biology, vol. 23, no. 6, pp. 739-748, 1993.

[47] J. Li, B. A. Hodgeman, and B. M. Christensen, "Involvement of peroxidase in chorion hardening in Aedes aegypti," Insect Biochemistry and Molecular Biology, vol. 26, no. 3, pp. 309-317, 1996. 

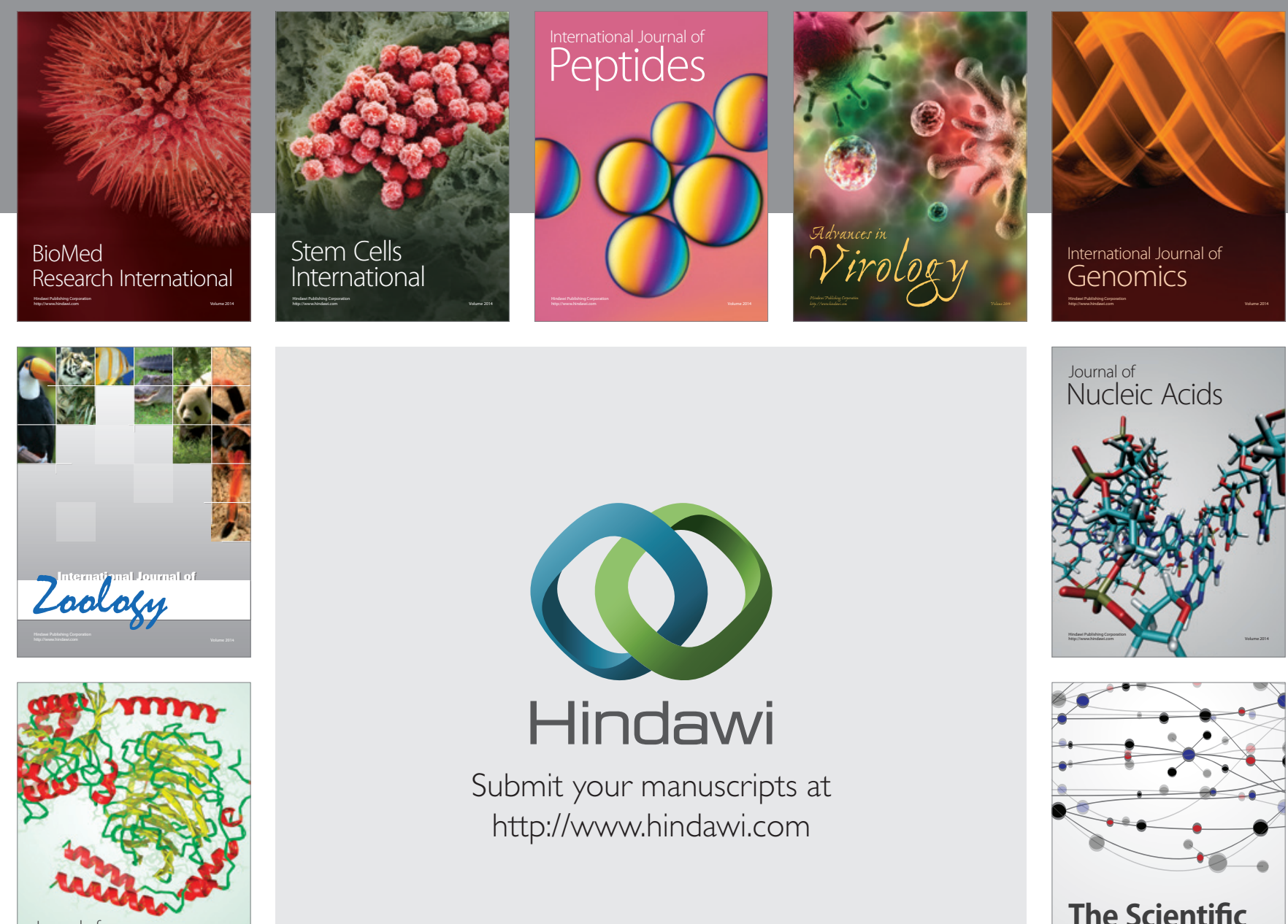

Submit your manuscripts at

http://www.hindawi.com

Journal of
Signal Transduction
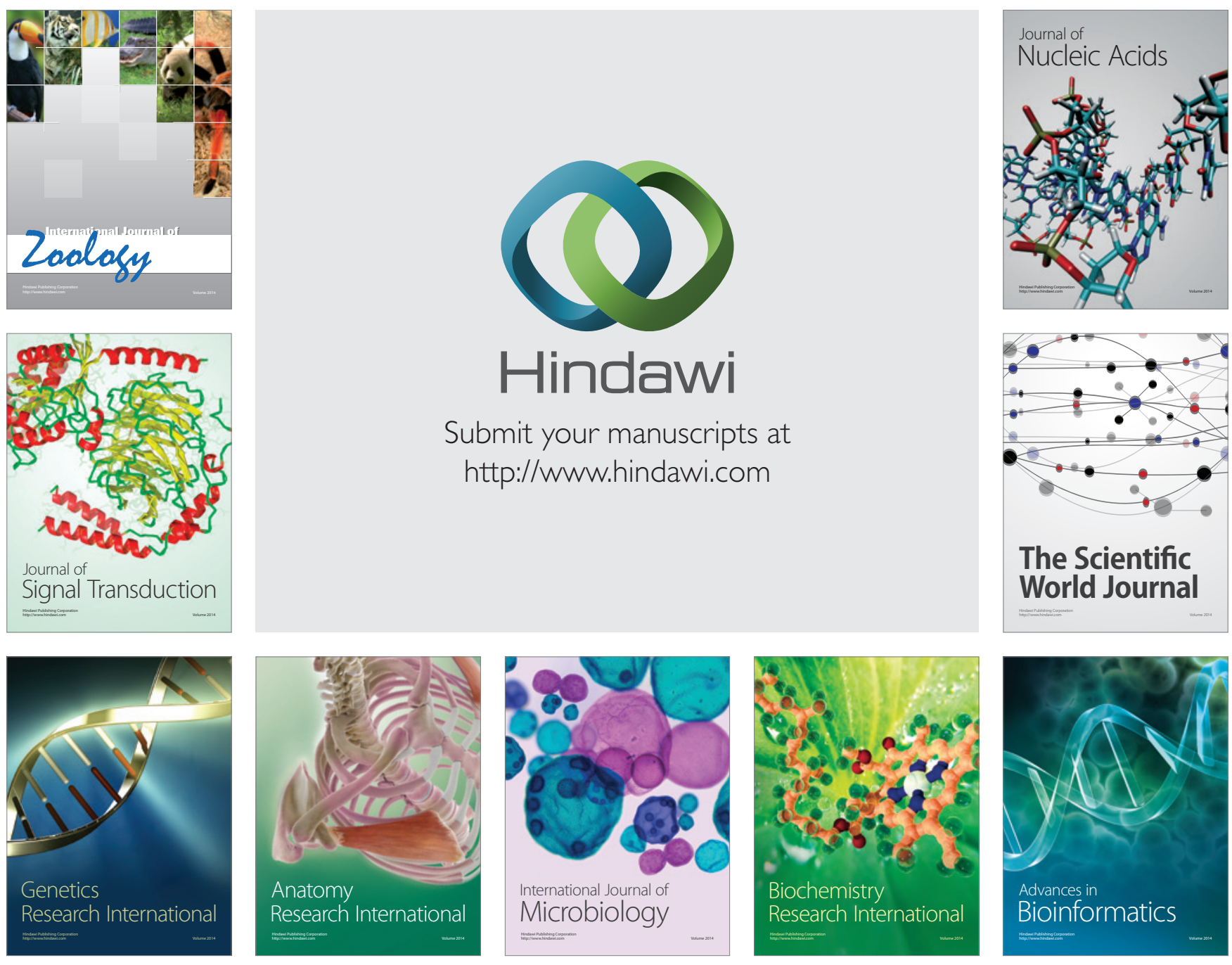

The Scientific World Journal
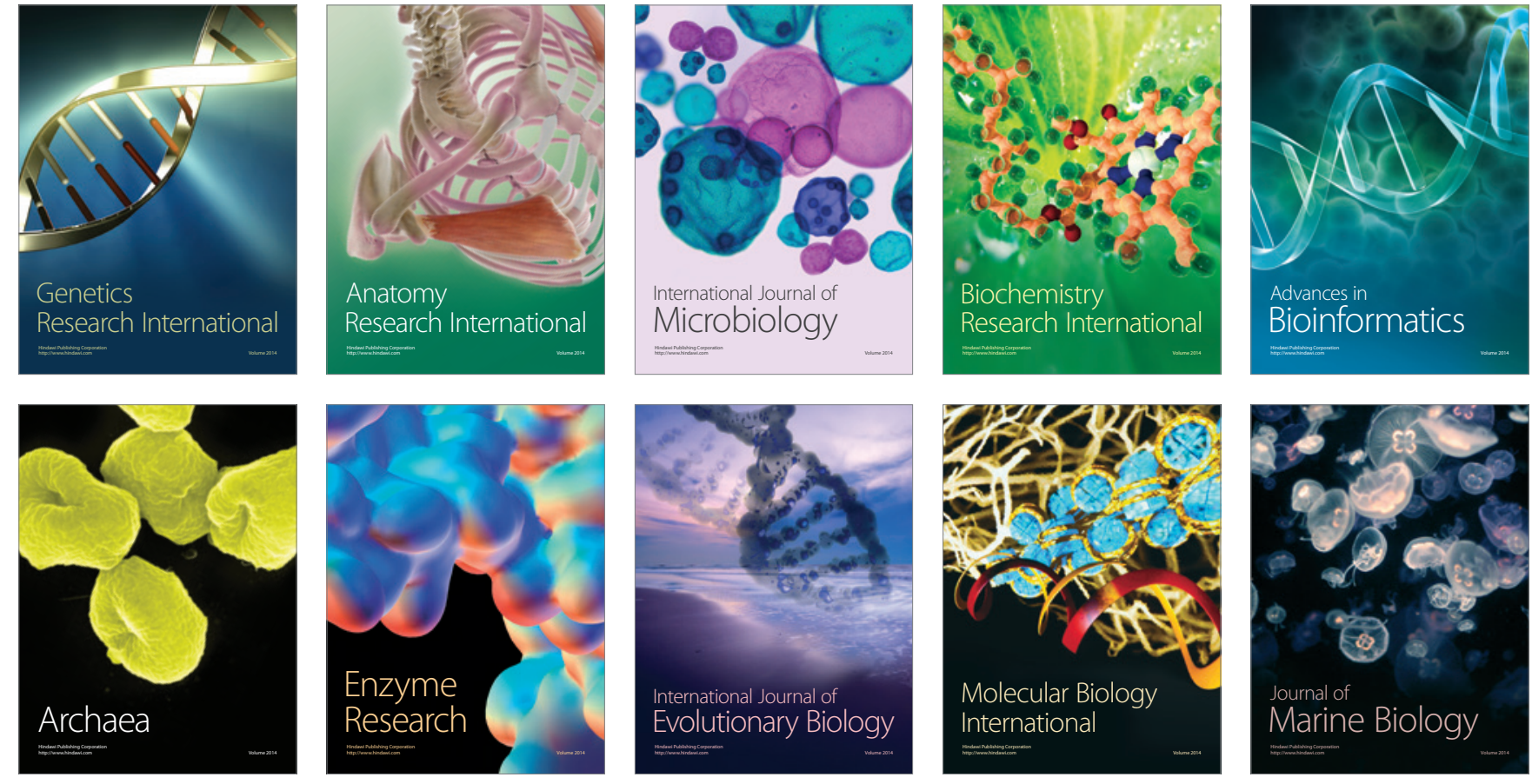